\title{
Principals' Decision-Making Practice in Government Preparatory Schools of West Shoa Zone, Oromia Regional State
}

\author{
Etecha Fekadu Dabesa ${ }^{1}$ \\ ${ }^{1}$ Department of Educational Planning and Management, College of Education and Behavioral Studies, \\ Wolkite University, Wolkite, Ethiopia \\ Correspondence: Etecha Fekadu Dabesa, Wolkite University, Wolkite, Ethiopia. \\ Email: fekadudabesa2017@gmail.com
}

doi: 10.23918/ijsses.v7i1p1

\begin{abstract}
The main purpose of this study was to assess the current principals' decision-making practice in government preparatory schools of West Shoa Zone, Oromia Regional State. To conduct this study, a quantitative research method particularly cross-sectional descriptive survey design was employed. A total of 233 respondents were included into the study. The data were collected through questionnaire, interview which was semi-structured, focus group discussion and document review. Data gathered through questionnaire were analyzed using percentage, frequency and chi-square. Data obtained through interview, focus group discussion and document review were qualitatively analyzed. The study revealed that the principals' decisionmaking practice in participating stakeholders in most areas of principals' decision-making practice of preparatory schools was unsatisfactory. Absence of participatory school leadership, lack of trust between stakeholders and principals were some of the factors that were found to have hindered principals' decisionmaking practice in schools. It was, thus, concluded that stakeholders' role in school decision-making was not given due attentions in preparatory schools under the study. This is likely to affect the overall activities of schools, in general, and decision-making practice, in particular. Based on the conclusion, consequently, it was recommended that woreda/district education office need to assign trained and experienced principals and train principals who can empower stakeholders to participate and improve the decision-making practices of schools.
\end{abstract}

Keywords: Decision-Making, Practices, Principals, Schools

\section{Introduction}

Schools are social centers that work with the community and are part of the community. The schools cannot exist separately from community. Schools need the assistance of community to accomplish their intended objective (UNESCO, 2014). This means that the local community, parents, teachers, students, principals, and woreda/district education office have to participate their best in all activities and in school decision making practice to achieve schools' objectives either individually or in groups. Groups are frequently used to solve problems and make decision in organizations. According to Walker (2000), using a group to make a decision has many potential advantages over decisions made by one individual or leader. As he states, they have more relevant knowledge and ideas to improve decision and their active participation would increase their understandings of decisions and commitment to implement the decisions to gain the intended objectives.

Decision making is still a central theme of research, policy and practice in business organizations as well as in schools (Chen \& Tjosvold, 2006). This theme has been the subject of extensive research for more 
than 30 years in education. In the past, principals throughout the world have been the main decision makers at school level. The increasing emergence of participatory decision making may be even more crucial today when schools struggle to reinvent themselves to respond to a growing demand for flexibility, concern for quality and the requirement of a high degree of commitment by stakeholders to their work (Marshall, 2012). Scholars and practitioners often conclude that the problems facing schools are too great for any one person to solve alone. Involving school stakeholders in the decision-making process offers a variety of potential benefits which can generate the social capacity necessary for excellent schools like improving the practice of the decisions, enhancing teacher motivation to their work and contributing to the quality of their work life (Somech, 2010). However, if organizations such as schools are to be effective, decisions have to be taken and implemented on various aspects like participating all stakeholders concerning areas needed for decision like students' discipline, budget management, teaching and learning process and school improvement related. Conflicts often arise between teachers and the school organization due to increasing desires for participatory role. Teachers sometimes complain of administrators overstepping their line of action and taking over administrative and disciplinary decisions that the teachers themselves could handle successfully. Many educational researchers have been expressing concern about participation of teachers in decision making. Most of them believe individuals derive personal satisfaction out of the feeling of recognition by the group and a sense of participation (Yelfign, 2010). In all organizations like schools, it is difficult to provide quality education without the active participation of community in general and through their representatives in particular. The community is expected to participate in the administration of schools through PTSA and KETB (MoE, 2010a).

ESDP IV (MoE, 2010a) considered improvement in school management and administration as one of the tools for improving education decision making at all levels. The government also launched the General Education Quality Improvement Program (GEQIP) in which school management and administration are taken as the key education quality intervention areas (Shibeshi, 2011). Oromia Education Bureau (2011) also indicated that for enhancing the effectiveness and efficiency of schools as well as providing quality education to the community participatory decision making is essential. Moreover, for enhancing schools' performance and students' achievement participatory decision making at school level is vital.

However, according to the annual report of preparatory schools' of West Shoa Zone in 2016, there are challenges faced by schools regarding teachers' motivation to their work and decisions made without their participation, low acceptance of decisions made by school management and low community participation in school activities like decision making and community contribution to education is low. According to De Grauwe et al. (2011), this may be due to lack of principals' decision-making practice by involving school stakeholders or other concerned bodies in different school decision making process and areas. Thus, the researcher was motivated to assess the current principals' decision-making practice in government preparatory schools of West Shoa Zone, Oromia Regional State.

\subsection{Statement of the Problem}

Decision making through involvement of the community strengthens school and community relation. It increases their involvement in instructional process which has a vital importance in bringing about quality of education, improving the overall teaching learning process and making the school compound attractive 
and promoting the school progress. In supporting this idea, De Grauwe et al. (2011) remarked that the involvement of school stakeholders in school management can help promote decision making at school level and improves the quality of schooling and students' achievement.

In principle, educational provision can be improved through better management practices, transparency in the use of resources and accountability to all stakeholders (community, parents, students, teachers, etc.). One of the advantages of involving communities in school decision making is that it creates a greater sense of ownership, morale and commitment among the stakeholders. Decisions that are made at local level are arguably more responsive to specific issues related to school contexts (Dunne et al. 2012).

In Ethiopia, some researchers have done researches on the schools' decision-making practices but all had their own limitation. For instance, Workneh Abebe (2012) studied on School Management and Decision Making in Ethiopian Government Schools' with the objective to examine the extent to which management at school level contributes to improved decision making. Even though, he studied on the population of all Ethiopian schools, he had taken a sample size of only 15 schools among which only 3 were from Oromia. His study was not only shallow but also did not represent all schools of Oromia Regional State or Ethiopian schools.

In Oromia Regional State, some researches have been carried out on school participative decision-making. For example; Balcha (2012) did an investigation of Teachers' Participation in Decision-Making Process in Bale Zone. Desalegn (2014) studied The Practices of Teachers' Involvement in Decision-Making in Government Secondary Schools of Jimma Town. Most recently, Olanie (2015) studied decision making practices of government secondary school leaders of Meta woreda of East Hararghe Zone of Oromia Regional State the finding of which showed that school stakeholders were not sufficiently participating in various aspects of core decision-making practices. Even this study was conducted on one woreda that consisted of only three secondary schools with few participants. Moreover, from the researcher's own 6 years work experience as an expert in one Woreda of the Zone, principals dominated decision making or informally organized groups were participating more in decision-making practices. Besides, there was no research conducted on the principals' decision-making practice in government preparatory schools of West Shoa Zone. These, thus, show the need to conduct further study by including more population from various groups of stakeholders of education to come up with more generalization because the previous focus on school leaders in at school structure but this was on principals' decision-making practice. Therefore, the main purpose of this study was to assess the principals decision-making practice in government preparatory schools of West Shoa Zone of Oromia Regional State because of the need to identify the practice of decision-making that has a lot to do with the deterioration of quality of education in the schools. To achieve the purpose of the study, the following basic questions would be dealt with:

1. To what extent do students, teachers, members of PTSA and KETB of schools take part in decision making in governmental preparatory schools of West Shoa Zone?

2. What factors affect the principals' decision-making practice in government preparatory schools of West Shoa Zone? 


\subsection{Objectives of the Study}

The study was aimed at assessing the current principals' decision-making practice in government preparatory schools of West Shoa Zone. The specific objectives of the study are to:

1. To identify the extent to which students, teachers, members of PTSA and KETB of schools take part in decision-making in governmental preparatory schools of West Shoa Zone.

2. To identify factors affect the principals' decision making practice in government preparatory schools of West Shoa Zone.

\subsection{Significance of the Study}

Unless all the concerned bodies were involved in decision-making, it is difficult, if not totally impossible, to attain the objectives of preparatory schools. There were bodies that should take part or contribute their share to schools so that intend objectives of schools were achieved.

Therefore, the study would specifically been significant to the zone understudy in the following points:

- It would enable the zone and WEOs, school supervisors, PTSA, KETB, teachers and students to know their responsibility and engage in participatory decision-making for the achievement of preparatory schools' objectives.

\subsection{Delimitation of the Study}

It was obvious that it would have been more useful to assess principals' decision-making practices in preparatory schools' at regional or national level as this provides with complete picture. But, for many practical reasons, this study would be delimited to assessing the principals' decision-making practice in 6/six/ government preparatory schools of West Shoa Zone of Oromia Regional State. It was also delimited to assessing factors affecting practice of decision making and the degree of involving stakeholders in practice of decision-making areas at preparatory schools of West Shoa Zone.

\section{Research Design and Methodology}

The study employed descriptive survey research design which is specifically cross-sectional survey design. This is because it enables the researcher to collect and describe large variety of data related to the decisionmaking practice within a short period of time. Moreover, this design is selected because it is appropriate when the aim of the study is to get an exact description of current status (Seyoum and Ayalew, as cited in Desalegn, 2014). As Creswell (2012) describes, cross-sectional survey has an advantage of measuring current conditions of attitude or practice and also examine current attitude, belief, opinion or practice. So, the researcher was eager to use this design because of its appropriateness to examine the decision-making practices and the ways individuals think about that practices in the schools.

\subsection{Research Method}

The studies employed both quantitative and qualitative approaches with more emphasis on quantitative as the leading method through close-ended questions and qualitative to support the quantitative data. To this end, the qualitative approach was incorporated in the study to validate and triangulate the quantitative data. 


\subsection{Sources of Data}

The researcher solicited data from both primary and secondary sources.

\section{a. Primary Sources}

Primary data were gathered from teachers, principals, members of students' council, heads of PTSA, and heads of KETB and school supervisors.

b. Secondary Sources

The secondary sources consisted of different recorded/written documents such as minutes of meeting in the schools.

\subsection{Population, Sample Size and Sampling Techniques}

In West Shoa Zone, there were 18 preparatory schools. Out of these schools, the researcher selected 6(six) or $33.3 \%$ by employing simple random sampling technique. This was because it gives equal chance for preparatory schools to be selected and the selection of those chosen did not affect the chance of others to be selected (Teddlile and Yu, as cited in Furi, 2016). Accordingly, Ejaji, Seyo, Bako, Gedo, Gudar and Ginchi preparatory schools, were selected.

Regarding the sample size of respondents, the selection was based on the idea of Creswell (2012) that says, "a general rule of thumb is to select as large sample as possible from the population". Singh and Masuku (2014) also support this idea by saying, "one approach is to use the entire population as the sample". Although cost considerations make this impossible for large populations, a census is more attractive for small populations (e.g., 200 or less). In this study, thus, because the total number of teachers was 179 , which was less than 200 , all of them participated in the study because of their number was manageable with time and other resources. 
Table 1: Population, Sample Size and Sampling Techniques

\begin{tabular}{|c|c|c|c|c|c|c|}
\hline No. & Name of school & Respondent & $\begin{array}{l}\text { Populati } \\
\text { on }\end{array}$ & Sample & $\%$ & $\begin{array}{l}\text { Sampling } \\
\text { Techniques }\end{array}$ \\
\hline \multirow{6}{*}{1} & \multirow{6}{*}{$\begin{array}{l}\text { Ejaji } \\
\text { Preparatory } \\
\text { School }\end{array}$} & Teachers & 20 & 20 & 100 & Census \\
\hline & & Principal & 1 & 1 & 100 & Availability \\
\hline & & $\begin{array}{l}\text { Students } \\
\text { members }\end{array}$ & 5 & 5 & 100 & Availability \\
\hline & & PTSA Head & 1 & 1 & 100 & Availability \\
\hline & & KETB Head & 1 & 1 & 100 & Availability \\
\hline & & Supervisor & 1 & 1 & 100 & Availability \\
\hline \multirow{6}{*}{2} & \multirow{6}{*}{$\begin{array}{l}\text { Seyo } \\
\text { Preparatory } \\
\text { School }\end{array}$} & Teachers & 21 & 21 & 100 & Census \\
\hline & & Principal & 1 & 1 & 100 & Availability \\
\hline & & $\begin{array}{l}\text { Students } \\
\text { members }\end{array}$ & 5 & 5 & 100 & Availability \\
\hline & & PTSA Head & 1 & 1 & 100 & Availability \\
\hline & & KETB Head & 1 & 1 & 100 & Availability \\
\hline & & Supervisor & 1 & 1 & 100 & Availability \\
\hline \multirow{6}{*}{3} & \multirow{6}{*}{$\begin{array}{l}\text { Bako } \\
\text { Preparatory } \\
\text { School }\end{array}$} & Teachers & 35 & 35 & 100 & Census \\
\hline & & Principal & 1 & 1 & 100 & Availability \\
\hline & & $\begin{array}{l}\text { Students council } \\
\text { members }\end{array}$ & 5 & 5 & 100 & Availability \\
\hline & & PTSA Head & 1 & 1 & 100 & Availability \\
\hline & & KETB Head & 1 & 1 & 100 & Availability \\
\hline & & Supervisor & 1 & 1 & 100 & Availability \\
\hline \multirow{6}{*}{4} & \multirow{6}{*}{$\begin{array}{l}\text { Gedo } \\
\text { Preparatory } \\
\text { School }\end{array}$} & Teachers & 38 & 38 & 100 & Census \\
\hline & & Principal & 1 & 1 & 100 & Availability \\
\hline & & $\begin{array}{l}\text { Students } \\
\text { members }\end{array}$ & 5 & 5 & 100 & Availability \\
\hline & & PTSA Head & 1 & 1 & 100 & Availability \\
\hline & & KETB Head & 1 & 1 & 100 & Availability \\
\hline & & Supervisor & 1 & 1 & 100 & Availability \\
\hline \multirow{6}{*}{5} & \multirow{6}{*}{$\begin{array}{l}\text { Gudar } \\
\text { Preparatory } \\
\text { School }\end{array}$} & Teachers & 35 & 35 & 100 & Census \\
\hline & & Principal & 1 & 1 & 100 & Availability \\
\hline & & $\begin{array}{ll}\text { Students council } \\
\text { members }\end{array}$ & 5 & 5 & 100 & Availability \\
\hline & & PTSA Head & 1 & 1 & 100 & Availability \\
\hline & & KETB Head & 1 & 1 & 100 & Availability \\
\hline & & Supervisor & 1 & 1 & 100 & Availability \\
\hline \multirow{6}{*}{6} & \multirow{6}{*}{$\begin{array}{l}\text { Ginchi } \\
\text { Preparatory } \\
\text { School }\end{array}$} & Teachers & 30 & 30 & 100 & Census \\
\hline & & Principal & 1 & 1 & 100 & Availability \\
\hline & & $\begin{array}{l}\text { Students } \\
\text { members }\end{array}$ & 5 & 5 & 100 & Availability \\
\hline & & PTSA Head & 1 & 1 & 100 & Availability \\
\hline & & KETB Head & 1 & 1 & 100 & Availability \\
\hline & & Supervisor & 1 & 1 & 100 & Availability \\
\hline \multicolumn{3}{|c|}{ Total } & 233 & 233 & 100 & Census \\
\hline
\end{tabular}

Source: West Shoa Zone Education Office Annual EMIS (2016) 


\subsection{Data Collection Tools}

Using different types of tools for gathering data help get adequate and sufficient data for the problem under study. In supporting this idea, John (2010) says that employing multiple methods of data collection helps the researcher combine the strength and amend some of the inadequacies when only one method is used independently.

\section{Questionnaires}

The main reason to use questionnaire was for obtaining factual information, opinions and attitudes from large number of subjects with-in a short period of time. Questionnaires included both open and closed ended items.

\section{Interviews}

The interview was prepared for heads of PTSA and KETB. The researcher used semi-structured interview which contained similar idea with the contents of the questionnaires.

\section{Focus group discussion}

Focus group discussion was conducted with 30 members of student council, 5 from each preparatory school. The focus group discussions were managed by the researcher himself. There were 6 FGD groups, i.e., 1 in each sample school for 30 minutes and each group consisted of 5 members from students' council.

\section{Document Review}

Documents were also reviewed for this study. The documents reviewed included teachers' minutes of meetings, PTSA's minutes of meetings, KETB' minutes of meetings, and minutes of students council in all the sample schools.

\subsection{Methods of Data Analysis}

In agreement with the data that were collected from respondents, the close-ended items were systematically coded, tabulated and organized for analysis. The organized and coded data were stored and analyzed using such descriptive statistics as percentage, frequency, mean and average mean; and inferential statistics (chi-square).

In addition to the above methods of data analysis, data obtained through interview, open- ended questions, and document review and focus group discussion were analyzed and interpreted qualitatively by describing or narrating the responses provided by the respondents.

\section{Results and Discussion of the Study}

Questionnaires were distributed to teachers, principals and school supervisors. One hundred and ninetyone (191) questionnaires were distributed to respondents and interestingly all were properly filled in and 
returned. In order to validate the data from questionnaire, interviews were conducted with heads of PTSA and KETB. Focus group discussions (FGD) were held with students' council members. Documents were also reviewed as supplementary data collecting tool.

Table 2: Extent of participation in decisions concerning school planning activities

\begin{tabular}{|c|c|c|c|c|c|c|c|c|c|c|}
\hline \multirow[t]{2}{*}{ No } & \multirow[t]{2}{*}{ Items } & \multirow{2}{*}{$\begin{array}{l}\text { Response } \\
\text { rating scale }\end{array}$} & \multicolumn{2}{|c|}{ School leaders } & \multicolumn{2}{|c|}{ Teachers } & \multicolumn{2}{|c|}{ Total } & \multirow[t]{2}{*}{$\mathrm{X}^{2}$} & \multirow[t]{2}{*}{ Sig. } \\
\hline & & & $F$ & $\%$ & $\mathrm{~F}$ & $\%$ & F & $\%$ & & \\
\hline \multirow[t]{5}{*}{1} & \multirow{5}{*}{$\begin{array}{l}\text { Planning } \\
\text { activities }\end{array}$} & $\mathrm{vH}$ & 0 & 0 & 11 & 6.1 & 11 & 5.8 & \multirow[t]{5}{*}{12.810} & \multirow[t]{5}{*}{.012} \\
\hline & & $\mathrm{H}$ & 5 & 41.7 & 22 & 12.3 & 27 & 14.1 & & \\
\hline & & $\mathrm{M}$ & 4 & 33.3 & 28 & 15.6 & 32 & 16.8 & & \\
\hline & & L & 1 & 8.3 & 59 & 33 & 60 & 31.4 & & \\
\hline & & VL & 2 & 16.7 & 59 & 33 & 61 & 31.9 & & \\
\hline \multirow[t]{5}{*}{2} & \multirow{5}{*}{$\begin{array}{l}\text { Setting the mission, } \\
\text { vision and values of } \\
\text { school }\end{array}$} & $\mathrm{VH}$ & 0 & 0 & 13 & 7.3 & 13 & 6.8 & \multirow[t]{5}{*}{5.595} & \multirow[t]{5}{*}{.231} \\
\hline & & $\mathrm{H}$ & 4 & 33.3 & 41 & 22.9 & 45 & 23.6 & & \\
\hline & & $\mathrm{M}$ & 2 & 16.7 & 32 & 17.9 & 34 & 17.8 & & \\
\hline & & $\mathrm{L}$ & 6 & 50 & 53 & 29.6 & 59 & 30.9 & & \\
\hline & & VL & 0 & 0 & 40 & 22.3 & 40 & 20.9 & & \\
\hline \multirow[t]{5}{*}{3} & \multirow{5}{*}{$\begin{array}{l}\text { Determining } \\
\text { mechanism } \\
\text { supervising } \\
\text { implementation }\end{array}$} & $\mathrm{VH}$ & 1 & 8.3 & 4 & 2.2 & 5 & 2.6 & \multirow[t]{5}{*}{10.857} & \multirow[t]{5}{*}{.028} \\
\hline & & $\mathrm{H}$ & 4 & 33.3 & 23 & 12.8 & 27 & 14.1 & & \\
\hline & & $\mathrm{M}$ & 5 & 41.7 & 41 & 22.9 & 46 & 24.1 & & \\
\hline & & $\mathrm{L}$ & 2 & 16.7 & 68 & 38 & 70 & 36.6 & & \\
\hline & & $\mathrm{VL}$ & 0 & 0 & 43 & 24 & 43 & 22.5 & & \\
\hline
\end{tabular}

With item 1 of Table 2, the respondents were asked to rate their participation in decisions like planning the school's activities. Accordingly, 2(16.7\%) and 59(33\%) of school leaders and teachers respectively rated as very low. On the other hand, $1(8.3 \%)$ and 59(33\%) of school leaders and teachers respectively rated as low. In addition, 4(33.3\%) and 28(15.6\%) of school leaders and teachers respectively rated as medium. Moreover, 5(41.7\%) and 22(12.3\%) of school leaders and teachers respectively rated as high. Furthermore, $0(0 \%)$ and $11(6.1 \%)$ of school leaders and teachers respectively rated as very high. However, the sum of the total respondents' percentage values rated $11(5.8 \%)$ as very high, $27(14.1 \%)$ as high, $32(16.8 \%)$ as medium, sixty $(31.4 \%)$ as low and $61(31.9 \%)$ as very low. To compare the agreement of school leaders and teachers on stakeholders' involvement in deciding on planning school activities the chisquare was computed and revealed $\mathrm{X}^{2}$ (12.810) sig. (.012). This implies that participative decision-making took place in this aspect of school area was low. In relation to this, the researcher analyzed different documents of the sample preparatory schools. Accordingly, it was learned that the school plans were prepared by principals, vice principals, supervisors and PTSA members of the schools. This shows that the participation of teachers, members of students' council and KETB was low which, in turn, would affect the implementation of school activities.

Item 2 of Table 2 relates to the extent of stakeholders' participation in decisions like setting mission, vision and values of the school. As regards this, $0(0 \%)$ and $40(22.3 \%)$ of school leaders and teachers respectively rated as very low. On the other hand, 6(50\%) and 53(29.6\%) of school leaders and teachers respectively rated as low. In addition, $2(16.7 \%)$ and $32(17.9 \%)$ of school leaders and teachers respectively rated as 
medium. Moreover, 4(33.3\%) and 41(22.9\%) of school leaders and teachers respectively rated as high. Furthermore, $0(0 \%)$ and $13(7.3 \%)$ of school leaders and teachers respectively rated as very high. However, the sum of the total respondents' percentage values rated $13(6.8 \%)$ as very high, $45(23.6 \%)$ as high, $34(17.8 \%)$ as medium, fifty nine $(30.9 \%)$ as low and $40(20.9 \%)$ as very low. To compare the agreement of school leaders and teachers on stakeholders' involvement in deciding on mission, vision and values of school the chi-square was computed and revealed $\mathrm{X}^{2}$ (5.595) sig. (.231). This implies that participative decision making took place in different aspects of school area was low. The interview with heads of PTSA and KETB showed that principals need to have the skill and ability in involving stakeholders in producing school mission, visions and values.

With item 3 of Table 2, the respondents were requested to rate the extent of participation of stakeholders in decisions like determining the mechanism of supervising plan implementation. Accordingly, $0(0 \%)$ and $43(24 \%)$ of school leaders and teachers respectively rated as very low. On the other hand, 2(16.7\%) and $68(38 \%)$ of school leaders and teachers respectively rated as low. In addition, 5(41.7\%) and 41(22.9\%) of school leaders and teachers respectively rated as medium. Moreover, 4(33.3\%) and 23(12.8\%) of school leaders and teachers respectively rated as high. Furthermore, 1(8.3\%) and 4(2.2\%) of school leaders and teachers respectively rated as very high. However, the sum of the total respondents' percentage values rated $5(2.6 \%)$ as very high, twenty-seven $(14.1 \%)$ as high, $46(24.1 \%)$ as medium, $70(36.6 \%)$ as low and $43(22.5 \%)$ as very low. To compare the agreement of school leaders and teachers on stakeholders' involvement in deciding the mechanism of supervising plan implementation the chi-square was computed and revealed $\mathrm{X}^{2}$ (10.857) sig. (.028). This implies that participative decision-making took place in different aspects of school area was low. In order to substantiate the above findings, interview was conducted with heads of PTSA and KETB. From their responses, it was learned that, most of the time, school plan is prepared by school principals, without involving stakeholders. That means school principals did not pay attention to participate stakeholders in planning and because of this, as the respondents remarked, stakeholders were also reluctant to participate in planning as well as supervising of the plan implementation as opposed to revised $\mathrm{MoE}$, (2010) guideline which requires the participation of all stakeholders in the school planning (strategic and annual plan). 
Table 3: Extent of participation in decisions concerning curriculum and Instruction

\begin{tabular}{|c|c|c|c|c|c|c|c|c|c|c|}
\hline \multirow{2}{*}{$\begin{array}{l}\mathrm{N} \\
\mathrm{o}\end{array}$} & \multirow[t]{2}{*}{ Items } & \multirow{2}{*}{$\begin{array}{l}\text { Response } \\
\text { rating scale }\end{array}$} & \multicolumn{2}{|c|}{ School leaders } & \multicolumn{2}{|c|}{ Teachers } & \multicolumn{2}{|c|}{ Total } & \multirow[t]{2}{*}{$\overline{X^{2}}$} & \multirow[t]{2}{*}{ Sig. } \\
\hline & & & $\mathrm{F}$ & $\%$ & $\mathrm{~F}$ & $\%$ & $\mathrm{~F}$ & $\%$ & & \\
\hline \multirow[t]{2}{*}{1} & \multirow{5}{*}{$\begin{array}{l}\text { Setting the } \\
\text { learning } \\
\text { objectives }\end{array}$} & VH & 0 & 0 & 13 & 7.3 & 13 & 6.8 & \multirow{5}{*}{4.410} & \multirow[t]{5}{*}{.353} \\
\hline & & $\mathrm{H}$ & 4 & 33.3 & 39 & 21.8 & 43 & $\begin{array}{l}22 . \\
5\end{array}$ & & \\
\hline & & M & 3 & 25 & 50 & 27.9 & 53 & 27.7 & & \\
\hline & & $\mathrm{L}$ & 5 & 41.7 & 48 & 26.8 & 53 & 27.7 & & \\
\hline & & VL & 0 & 0 & 29 & 16.2 & 29 & 15.2 & & \\
\hline \multirow[t]{5}{*}{2} & \multirow{5}{*}{$\begin{array}{l}\text { Deciding on } \\
\text { the format of } \\
\text { lesson plan }\end{array}$} & VH & 1 & 8.3 & 18 & 10.1 & 19 & 9.9 & \multirow[t]{5}{*}{4.196} & \multirow[t]{5}{*}{.380} \\
\hline & & $\mathrm{H}$ & 2 & 16.7 & 45 & 25.1 & 47 & 24.6 & & \\
\hline & & M & 5 & 41.7 & 40 & 22.3 & 45 & 23.6 & & \\
\hline & & $\mathrm{L}$ & 4 & 33.3 & 48 & 26.8 & 52 & 27.2 & & \\
\hline & & VL & 0 & 0 & 28 & 15.6 & 28 & 14.7 & & \\
\hline \multirow[t]{5}{*}{3} & \multirow{5}{*}{$\begin{array}{l}\text { Evaluating } \\
\text { how well the } \\
\text { department is } \\
\text { operating }\end{array}$} & VH & 2 & 16.7 & 10 & 5.6 & 12 & 6.3 & \multirow[t]{5}{*}{3.735} & \multirow[t]{5}{*}{.443} \\
\hline & & $\mathrm{H}$ & 4 & 33.3 & 45 & 25.1 & 49 & 25.7 & & \\
\hline & & M & 4 & 33.3 & 79 & 44.1 & 83 & 43.5 & & \\
\hline & & $\mathrm{L}$ & 2 & 16.7 & 31 & 17.3 & 33 & 17.3 & & \\
\hline & & VL & 0 & 0 & 14 & 7.8 & 14 & 7.3 & & \\
\hline \multirow[t]{5}{*}{4} & \multirow{5}{*}{$\begin{array}{l}\text { Developing } \\
\text { procedures } \\
\text { for assessing } \\
\text { student } \\
\text { achievement }\end{array}$} & VH & 2 & 16.7 & 15 & 8.4 & 17 & 8.9 & \multirow[t]{5}{*}{6.251} & \multirow[t]{5}{*}{.181} \\
\hline & & $\mathrm{H}$ & 2 & 16.7 & 34 & 19 & 36 & 18.8 & & \\
\hline & & M & 7 & 58.3 & 58 & 32.4 & 65 & 34 & & \\
\hline & & $\mathrm{L}$ & 1 & 8.3 & 45 & 25.1 & 46 & 24.1 & & \\
\hline & & VL & 0 & 0 & 27 & 15.1 & 27 & 14.1 & & \\
\hline \multirow[t]{5}{*}{5} & \multirow{5}{*}{$\begin{array}{l}\text { Determining } \\
\text { when } \\
\text { instructional } \\
\text { supervision } \\
\text { can be }\end{array}$} & VH & 2 & 16.7 & 8 & 4.5 & 10 & 5.2 & \multirow[t]{5}{*}{8.056} & \multirow[t]{5}{*}{.090} \\
\hline & & $\mathrm{H}$ & 4 & 33.3 & 29 & 16.2 & 33 & 17.3 & & \\
\hline & & $M$ & 3 & 25 & 37 & 20.7 & 40 & 20.9 & & \\
\hline & & $\mathrm{L}$ & 3 & 25 & 73 & 40.8 & 76 & 39.8 & & \\
\hline & & VL & 0 & 0 & 32 & 17.9 & 32 & 16.8 & & \\
\hline
\end{tabular}

As can be observed from Table 3, item 1, relates to the extent of participation of stakeholders in decisions like setting the learning objectives. As regards this, $0(0 \%)$ and 29(16.2\%) of school leaders and teachers respectively rated as very low. On the other hand, 5(41.7\%) and 48(26.8\%) of school leaders and teachers respectively rated as low. In addition, 3(25\%) and 50(27.9\%) of school leaders and teachers respectively rated as medium. Moreover, 4(33.3\%) and 39(21.8\%) of school leaders and teachers respectively rated as high. Furthermore, $0(0 \%)$ and $13(7.3 \%)$ of school leaders and teachers respectively rated as very high. However, the sum of the total respondents' percentage values rated 13(6.8\%) as very high, 43(22.5\%) as high, 53(27.7\%) as medium, 53(27.7\%) as low and 29(15.2\%) as very low. To compare the agreement of school leaders and teachers on stakeholders' involvement in deciding the learning objectives, the chisquare was computed and revealed $\mathrm{X}^{2}$ (4.410) sig. (.353).

As shown in Table 3, item 2, was about the extent of the respondents' participation in decisions like deciding on the format of lesson plan. Accordingly, $0(0 \%)$ and $28(15.6 \%)$ of school leaders and teachers respectively rated as very low. On the other hand, 4(33.3\%) and 48(26.8\%) of school leaders and teachers 
respectively rated as low. In addition, 5(41.7\%) and 40(22.3\%) of school leaders and teachers respectively rated as medium. Moreover, $2(16.7 \%)$ and $45(25.1 \%)$ of school leaders and teachers respectively rated as high. Furthermore, 1(8.3\%) and 18(10.1\%) of school leaders and teachers respectively rated as very high. However, the sum of the total respondents' percentage values rated $19(9.9 \%)$ as very high, $47(24.6 \%)$ as high, $45(23.6 \%)$ as medium, fifty-two $(27.2 \%)$ as low and $28(14.7 \%)$ as very low. To compare the agreement of school leaders and teachers on stakeholders' involvement in deciding the format of lesson plan the chi-square was computed and revealed $\mathrm{X}^{2}$ (4.196) sig. (.380).

With item 3 of Table 3, the respondents were asked to rate the extent of participation in decisions like evaluating how well the department was operating. As regards this, $0(0 \%)$ and 14(7.8\%) of school leaders and teachers respectively rated as very low. On the other hand, $2(16.7 \%)$ and thirty one $(17.3 \%)$ of school leaders and teachers respectively rated as low. In addition, 4(33.3\%) and seventy-nine (44.1\%) of school leaders and teachers respectively rated as medium. Moreover, four (33.3\%) and 45(25.1\%) of school leaders and teachers respectively rated as high. Furthermore, 2(16.7\%) and 10(5.6\%) of school leaders and teachers respectively rated as very high. However, the sum of the total respondents' percentage values rated $12(6.3 \%)$ as very high, forty-nine (25.7\%) as high, 83(43.5\%) as medium, 33(17.3\%) as low and $14(7.3 \%)$ as very low. To compare the agreement of school leaders and teachers on stakeholders' involvement in deciding evaluating how well the department was operating the chi-square was computed and revealed $\mathrm{X}^{2}$ (3.735) sig. (.443).

With regard to assessing participation in decisions like developing procedures for assessing student achievement, item 4 of Table 3, $0(0 \%)$ and $27(15.1 \%)$ of school leaders and teachers respectively rated as very low. On the other hand, $1(8.3 \%)$ and $45(25.1 \%)$ of school leaders and teachers respectively rated as low. In addition, $7(58.3 \%)$ and $58(32.4 \%)$ of school leaders and teachers respectively rated as medium. Moreover, 2(16.7\%) and 34(19\%) of school leaders and teachers respectively rated as high. Furthermore, $2(16.7 \%)$ and $15(8.4 \%)$ of school leaders and teachers respectively rated as very high. However, the sum of the total respondents' percentage values rated $17(8.9 \%)$ as very high, 36(18.8\%) as high, 65(34\%) as medium, $46(24.1 \%)$ as low and $27(14.1 \%)$ as very low. To compare the agreement of school leaders and teachers on stakeholders' involvement in deciding how to develop procedures for assessing student achievement the chi-square was computed and revealed $\mathrm{X}^{2}$ (6.251) sig. (.181).

With item 5 of Table 3, the respondents were requested to rate the extent of their participation in decisions like determining when instructional supervision could be conducted. As regards this, $0(0 \%)$ and $32(17.9 \%)$ of school leaders and teachers respectively rated as very low. On the other hand, 3(25\%) and 73(40.8\%) of school leaders and teachers respectively rated as low. In addition, 3(25\%) and 37(20.7\%) of school leaders and teachers respectively rated as medium. Moreover, 4(33.3\%) and 29(16.2\%) of school leaders and teachers respectively rated as high. Furthermore, 2(16.7\%) and 8(4.5\%) of school leaders and teachers respectively rated as very high. However, the sum of the total respondents' percentage values rated $10(5.2 \%)$ as very high, thirty-three (17.3\%) as high, $40(20.9 \%)$ as medium, 76(39.8\%) as low and $32(16.8 \%)$ as very low. To compare the agreement of school leaders and teachers on stakeholders' involvement in deciding when instructional supervision could be conducted the chi-square was computed and revealed $\mathrm{X}^{2}$ (8.056) sig. (.090). This implies that participative decision-making took place in this aspect of school area was low. Results obtained from some documents such as staff minutes of meeting 
supported the finding of the above table. The minutes indicated that teachers had participated in asking for supplementary reference books, evaluating textbooks, conducting action researches, producing teaching aids and exchange of good experience, teaching normal class and supporting students by makeup and tutorial classes. In other words, curriculum implementation and instructional improvement were among the major operational activities in school system. It is a core in both at the school and the national level. This finding is supported by Aggrwal's (2014) finding in which he pointed out that individual and cooperative efforts by teachers to decide when, how and what to teach, to revise courses, select content, plan units and produce teaching aids have become a common practice.

Table 4: Extent of participation in decisions concerning school budget and income generation

\begin{tabular}{|c|c|c|c|c|c|c|c|c|c|c|}
\hline $\mathrm{N}$ & Items & Response & & eaders & Teac & & Tot & & $\mathrm{X}^{2}$ & Sig. \\
\hline o & & rating scale & F & $\%$ & $\mathrm{~F}$ & $\%$ & $\mathrm{~F}$ & $\%$ & & \\
\hline 1 & Formulation & VH & 0 & 0 & 3 & 1.7 & 3 & 1.6 & 6.282 & .179 \\
\hline & school budget & $\mathrm{H}$ & 3 & 25 & 28 & 15.6 & 31 & 16.2 & & \\
\hline & & M & 2 & 16.7 & 24 & 13.4 & 26 & 13.6 & & \\
\hline & & $\mathrm{L}$ & 6 & 50 & 48 & 26.8 & 54 & 28.3 & & \\
\hline & & VL & 1 & 8.3 & 76 & 42.5 & 77 & 40.3 & & \\
\hline 2 & Determining means & VH & 2 & 16.7 & 5 & 2.8 & 7 & 3.7 & 8.773 & .067 \\
\hline & of income & $\mathrm{H}$ & 1 & 8.3 & 17 & 9.5 & 18 & 9.4 & & \\
\hline & generation & M & 3 & 25 & 34 & 19 & 37 & 19.4 & & \\
\hline & & $\mathrm{L}$ & 5 & 41.7 & 60 & 33.5 & 65 & 34 & & \\
\hline & & VL & 1 & 8.3 & 63 & 35.2 & 64 & 33.5 & & \\
\hline 3 & Sharing of budget & VH & 0 & 0 & 0 & 0 & 0 & 0 & 9.635 & .022 \\
\hline & for the department & $\mathrm{H}$ & 0 & 0 & 10 & 5.6 & 10 & 5.2 & & \\
\hline & & M & 3 & 25 & 21 & 11.7 & 24 & 12.6 & & \\
\hline & & $\mathrm{L}$ & 7 & 58.3 & 47 & 26.3 & 54 & 28.3 & & \\
\hline & & VL & 2 & 16.7 & 101 & 56.4 & 103 & 53.9 & & \\
\hline 4 & Implementation of & VH & 0 & 0 & 2 & 1.1 & 2 & 1 & 3.704 & .448 \\
\hline & school budget & $\mathrm{H}$ & 2 & 16.7 & 23 & 12.8 & 25 & 13.1 & & \\
\hline & & M & 4 & 33.3 & 33 & 18.4 & 37 & 19.4 & & \\
\hline & & $\mathrm{L}$ & 5 & 41.7 & 64 & 35.8 & 69 & 36.1 & & \\
\hline & & VL & 1 & 8.3 & 57 & 31.8 & 58 & 30.4 & & \\
\hline 5 & Follow up of school & VH & 2 & 16.7 & 3 & 1.7 & 5 & 2.6 & 14.612 & .006 \\
\hline & budget performance & $\mathrm{H}$ & 2 & 16.7 & 28 & 15.6 & 30 & 15.7 & & \\
\hline & & M & 3 & 25 & 28 & 15.6 & 31 & 16.2 & & \\
\hline & & $\mathrm{L}$ & 5 & 41.7 & 59 & 33 & 64 & 33.5 & & \\
\hline & & VL & 0 & 0 & 61 & 34.1 & 61 & 31.9 & & \\
\hline
\end{tabular}

As shown in Table 4, item 1, relates to participation of stakeholders in decisions like formulation of school budget. As could be seen from the responses, 1(8.3\%) and 76(42.5\%) of school leaders and teachers respectively rated as very low. On the other hand, 6(50\%) and 48(26.8\%) of school leaders and teachers respectively rated as low. In addition, 2(16.7\%) and 24(13.4\%) of school leaders and teachers respectively rated as medium. Moreover, $3(25 \%)$ and $28(15.6 \%)$ of school leaders and teachers respectively rated as high. Furthermore, $0(0 \%)$ and $3(1.7 \%)$ of school leaders and teachers respectively rated as very high. However, the sum of the total respondents' percentage values rated $3(1.6 \%)$ as very high, 31(16.2\%) as high, $26(13.6 \%)$ as medium, fifty-four $(28.3 \%)$ as low and $77(40.3 \%)$ as very low. To compare the agreement of school leaders and teachers on stakeholders' involvement in deciding formulation of school budget the chi-square was computed and revealed $X^{2}$ (8.056) sig. (.090). In order to substantiate the above 
findings, the researcher conducted an interview with PTSA and KETB heads. Accordingly, one PTSA head explained "teachers and students did not participate in the formulation of school budget. As to the reasons, the interviewee expressed that there was less attention to teachers and students, participation and that; most teachers and students believed that preparing school budget is the duty of principals and some selected committee." Contrary to this finding, the policy directives of the Ministry of Education (MoE, 2010b) clearly indicated that school community contributions and involvement in schooling were important means of financing education.

As can be noticed from Table 4, item 2 was about participation of stakeholders in decisions like determining means of income generation. Accordingly, 1(8.3\%) and 63(35.2\%) of school leaders and teachers respectively rated as very low. On the other hand, 5(41.7\%) and 60(33.5\%) of school leaders and teachers respectively rated as low. In addition, 3(25\%) and 34(19\%) of school leaders and teachers respectively rated as medium. Moreover, $1(8.3 \%)$ and $17(9.5 \%)$ of school leaders and teachers respectively rated as high. Furthermore, 2(16.7\%) and 5(2.8\%) of school leaders and teachers respectively rated as very high. However, the sum of the total respondents' percentage values rated $7(3.7 \%)$ as very high, $18(9.4 \%)$ as high, 37(19.4\%) as medium, 65(34\%) as low and 64(33.5\%) as very low. To compare the agreement of school leaders and teachers on stakeholders' involvement in deciding determining means of income generation the chi-square was computed and revealed $X^{2}$ (8.773) sig. (.067). This implies that participative decision making took place in this aspect of school area was low. As regards this item the researcher conducted an interview with PTSA and KETB heads who, in their responses, explained the very existence of different problems in the schools. According to their responses, school principals and other personnel who were working in financial management positions lacked experience and also that they did not have training on educational finance management. This lack of experience and training constrained them to involve stakeholders in determining means of income generation that would benefit school as a whole.

With item 3 of Table 4, the respondents rated the level of participation of stakeholders in decisions concerning budget sharing for the department. As could be seen from the responses, $2(16.7 \%)$ and $101(56.4 \%)$ of school leaders and teachers respectively rated as very low. On the other hand, 7(58.3\%) and $47(26.3 \%)$ of school leaders and teachers respectively rated as low. In addition, $3(25 \%)$ and $21(11.7 \%)$ of school leaders and teachers respectively rated as medium. Moreover, $0(0 \%)$ and 10(5.6\%) of school leaders and teachers respectively rated as high. Furthermore, $0(0 \%)$ and $0(0 \%)$ of school leaders and teachers respectively rated as very high. However, the sum of the total respondents' percentage values rated $0(0 \%)$ as very high, $10(5.2 \%)$ as high, $24(12.6 \%)$ as medium, 54(28.3\%) as low and 103(53.9\%) as very low. To compare the agreement of school leaders and teachers on stakeholders' involvement in deciding budget sharing for the department the chi-square was computed and revealed $\mathrm{X}^{2}(9.635)$ sig. (.022).

Item 4 of Table 4, has to do with the respondents' level of participation in follow up of implementation of school budget. Accordingly, 1(8.3\%) and 57(31.8\%) of school leaders and teachers respectively rated as very low. On the other hand, 5(41.7\%) and 64(35.8\%) of school leaders and teachers respectively rated as low. In addition, $4(33.3 \%)$ and $33(18.4 \%)$ of school leaders and teachers respectively rated as medium. Moreover, 2(16.7\%) and 23(12.8\%) of school leaders and teachers respectively rated as high. Furthermore, $0(0 \%)$ and $2(1.1 \%)$ of school leaders and teachers respectively rated as very high. However, the sum of 
the total respondents' percentage values rated $2(1 \%)$ as very high, $25(13.1 \%)$ as high, $37(19.4 \%)$ as medium, $69(36.1 \%)$ as low and 58(30.4\%) as very low. To compare the agreement of school leaders and teachers on stakeholders' involvement in deciding the follow up of implementation of school budget the chi-square was computed and revealed $\mathrm{X}^{2}$ (3.704) sig. (.448). This implies that participative decision making took place in this aspect of school area was low. Moreover, documents reviewed like minutes of PTSA and KETB meetings indicated that their involvement in following up of income and expenditure, means of income generation, through attempts have been there, generally, was minimal.

In their responses to item 5 of Table 4, the respondents rated the level of their participation in decisions like following up of school budget performance. As could be seen from the responses, $0(0 \%)$ and $61(34.1 \%)$ of school leaders and teachers respectively rated as very low. On the other hand, 5(41.7\%) and $59(33 \%)$ of school leaders and teachers respectively rated as low. In addition, 3(25\%) and 28(15.6\%) of school leaders and teachers respectively rated as medium. Moreover, 2(16.7\%) and 28(15.6\%) of school leaders and teachers respectively rated as high. Furthermore, 2(16.7\%) and 3(1.7\%) of school leaders and teachers respectively rated as very high. However, the sum of the total respondents' percentage values rated $5(2.6 \%)$ as very high, $30(15.7 \%)$ as high, 31(16.2\%) as medium, 64(33.5\%) as low and 61(31.9\%) as very low. To compare the agreement of school leaders and teachers on stakeholders' involvement in deciding the following up of school budget performance the chi-square was computed and revealed $\mathrm{X}^{2}$ (14.612) sig. (.006). This implies that participative decision-making took place in this aspect of school area was low. To substantiate the data concerning the practice of participating stakeholders in the preparation of school budgeting and income generation decisions, the researcher conducted interview with PTSA and KETB heads which revealed that there was a low extent of teachers', supervisors' and members of student councils participation in this particular decision-making practice category. The interviewed PTSA and KETB heads particularly said, "Decisions concerning school budget is seen in schools as not a mandate of teachers, supervisors or student councils, rather the mandate is given to PTSA and KETB committee. The teachers and students may participate through their one or two representatives." From this, one could realize that in preparatory schools under the sample study, stakeholders' participation in decisions regarding school budget was typically indirect and limited. In addition to interview, the researcher examined budget record documents as well as minutes of PTSA and KETB meetings. The document contained budgets collected from internal income (revenue) which was evaluated and approved by PTSA and KETB committee. It was, however, learned that teachers and students were not part of the decisions made concerning school budget to the level expected as there was nominal involvement through one or two individuals which then, was not direct at all.

In general, although the findings of different scholars underline the importance, principals of the schools under the study did not adequately involve stakeholders in school budget allocation, approval, implementation, follow up and evaluation. As regards this Emeneke (2014), written, the fact that when people are part of decision-making process, there is greater opportunity of expression of mind, ideas, existing disputes and more occasions for disagreements and agreement. Yet, the finding revealed that the principals did not adequately participate stakeholders (teachers, vice principals, supervisors and students) in decisions concerning budget although involvement would help solicit valuable suggestions, opinions and criticisms before decisions made school budget. 
Table 5: Extent of participation in decisions concerning school building

\begin{tabular}{|c|c|c|c|c|c|c|c|c|c|c|}
\hline \multirow[t]{2}{*}{$\begin{array}{l}\mathrm{N} \\
\mathrm{o}\end{array}$} & \multirow[t]{2}{*}{ Items } & \multirow{2}{*}{$\begin{array}{l}\text { Response } \\
\text { rating } \\
\text { scale }\end{array}$} & \multicolumn{2}{|c|}{$\begin{array}{l}\text { School } \\
\text { leaders }\end{array}$} & \multicolumn{2}{|c|}{ Teachers } & \multicolumn{2}{|c|}{ Total } & \multirow[t]{2}{*}{$X^{2}$} & \multirow[t]{2}{*}{ Sig. } \\
\hline & & & $\mathrm{F}$ & $\%$ & $\mathrm{~F}$ & $\%$ & $\mathrm{~F}$ & $\%$ & & \\
\hline \multirow[t]{5}{*}{1} & \multirow{5}{*}{$\begin{array}{l}\text { Deciding on the expansion } \\
\text { of school buildings }\end{array}$} & VH & 1 & 8.3 & 5 & 2.8 & 6 & 3.1 & \multirow{5}{*}{$\begin{array}{l}18.06 \\
2\end{array}$} & \multirow[t]{5}{*}{.001} \\
\hline & & $\mathrm{H}$ & 0 & 0 & 19 & 10.6 & 19 & 9.9 & & \\
\hline & & $\mathrm{M}$ & 7 & 58.3 & 25 & 14 & 32 & 16.8 & & \\
\hline & & $\mathrm{L}$ & 2 & 16.7 & 67 & 37.4 & 69 & 36.1 & & \\
\hline & & VL & 2 & 16.7 & 63 & 35.2 & 65 & 34 & & \\
\hline \multirow[t]{5}{*}{2} & \multirow{5}{*}{$\begin{array}{l}\text { Deciding on maintenance } \\
\text { of school buildings }\end{array}$} & VH & 1 & 8.3 & 4 & 2.2 & 5 & 2.6 & \multirow[t]{5}{*}{7.571} & \multirow[t]{5}{*}{.109} \\
\hline & & $\mathrm{H}$ & 2 & 16.7 & 18 & 10.1 & 20 & 10.5 & & \\
\hline & & M & 5 & 41.7 & 32 & 17.9 & 37 & 19.4 & & \\
\hline & & $\mathrm{L}$ & 2 & 16.7 & 63 & 35.2 & 65 & 34 & & \\
\hline & & VL & 2 & 16.7 & 62 & 34.6 & 64 & 33.5 & & \\
\hline \multirow[t]{5}{*}{3} & \multirow{5}{*}{$\begin{array}{l}\text { Deciding on the } \\
\text { construction of new } \\
\text { buildings }\end{array}$} & VH & 1 & 8.3 & 3 & 1.7 & 4 & 2.1 & \multirow{5}{*}{$\begin{array}{l}10.01 \\
9\end{array}$} & \multirow[t]{5}{*}{.040} \\
\hline & & $\mathrm{H}$ & 0 & 0 & 9 & 5 & 9 & 4.7 & & \\
\hline & & M & 5 & 41.7 & 25 & 14 & 30 & 15.7 & & \\
\hline & & $\mathrm{L}$ & 2 & 16.7 & 67 & 37.4 & 69 & 36.1 & & \\
\hline & & VL & 4 & 33.3 & 75 & 41.9 & 79 & 41.4 & & \\
\hline \multirow[t]{5}{*}{4} & \multirow{5}{*}{$\begin{array}{l}\text { Assigning school building } \\
\text { for administrative, } \\
\text { department and teaching } \\
\text { room purpose }\end{array}$} & VH & 1 & 8.3 & 7 & 3.9 & 8 & 4.2 & \multirow[t]{5}{*}{5.936} & \multirow[t]{5}{*}{.204} \\
\hline & & $\mathrm{H}$ & 0 & 0 & 21 & 11.7 & 21 & 11 & & \\
\hline & & M & 5 & 41.7 & 34 & 19 & 39 & 20.4 & & \\
\hline & & $\mathrm{L}$ & 4 & 33.3 & 54 & 30.2 & 58 & 30.4 & & \\
\hline & & VL & 2 & 16.7 & 63 & 35.2 & 65 & 34 & & \\
\hline
\end{tabular}

From the responses to item 1 of Table 5, which relates to the level of participation in decisions concerning the expansion of school buildings, 2(16.7\%) and 63(35.2\%) of school leaders and teachers respectively rated as very low. On the other hand, 2(16.7\%) and 67(37.4\%) of school leaders and teachers respectively rated as low. In addition, $7(58.3 \%)$ and $25(14 \%)$ of school leaders and teachers respectively rated as medium. Moreover, $0(0 \%)$ and $19(10.6 \%)$ of school leaders and teachers respectively rated as high. Furthermore, $1(8.3 \%)$ and $5(2.8 \%)$ of school leaders and teachers respectively rated as very high. However, the sum of the total respondents' percentage values rated $6(3.1 \%)$ as very high, 19(9.9\%) as high, $32(16.8 \%)$ as medium, sixty-nine $(36.1 \%)$ as low and $65(34 \%)$ as very low. To compare the agreement of school leaders and teachers on stakeholders' involvement in deciding expansion of school buildings the chi-square was computed and revealed $\mathrm{X}^{2}$ (18.062) sig. (.001).

As can be seen from responses to item 2 of Table 5 regarding the level of participation in decisions like deciding on maintenance of school buildings, $2(16.7 \%)$ and $62(34.6 \%)$ of school leaders and teachers respectively rated as very low. On the other hand, $2(16.7 \%)$ and $63(35.2 \%)$ of school leaders and teachers respectively rated as low. In addition, $5(41.7 \%)$ and $32(17.9 \%)$ of school leaders and teachers respectively rated as medium. Moreover, $2(16.7 \%)$ and $18(10.1 \%)$ of school leaders and teachers respectively rated as high. Furthermore, $1(8.3 \%)$ and $4(2.2 \%)$ of school leaders and teachers respectively rated as very high. However, the sum of the total respondents' percentage values rated $5(2.6 \%)$ as very high, 20(10.5\%) as 
high, 37(19.4\%) as medium, 65(34\%) as low and 64(33.5\%) as very low. To compare the agreement of school leaders and teachers on stakeholders' involvement in deciding maintenance of school buildings the chi-square was computed and revealed $\mathrm{X}^{2}$ (7.571) sig. (.109).

Item 3 of Table 5 has to do with the level of participation of stakeholders in decisions like deciding on the construction of new buildings. As to this, 4(33.3\%) and 75(41.9\%) of school leaders and teachers respectively rated as very low. On the other hand, $2(16.7 \%)$ and $67(37.4 \%)$ of school leaders and teachers respectively rated as low. In addition, 5(41.7\%) and 25(14\%) of school leaders and teachers respectively rated as medium. Moreover, $0(0 \%)$ and $9(5 \%)$ of school leaders and teachers respectively rated as high. Furthermore, $1(8.3 \%)$ and $3(1.7 \%)$ of school leaders and teachers respectively rated as very high. However, the sum of the total respondents' percentage values rated $4(2.1 \%)$ as very high, $9(4.7 \%)$ as high, $30(15.7 \%)$ as medium, $69(36.1 \%)$ as low and $79(41.4 \%)$ as very low. To compare the agreement of school leaders and teachers on stakeholders' involvement in deciding construction of new buildings the chi-square was computed and revealed $\mathrm{X}^{2}$ (10.019) sig. (.040). This implies that participative decision-making took place in this aspect of school area was low. According to Prowler (2011), creating a successful highperformance building in school organization requires an interactive approach starting from the design process which as the finding revealed, was lacking in the preparatory schools under the study.

As can be understood from item 4 of Table 5, the respondents were asked their level of participation in decisions like assigning school building for administrative, department and teaching rooms' purpose. As to this, $2(16.7 \%)$ and $63(35.2 \%)$ of school leaders and teachers respectively rated as very low. On the other hand $4(33.3 \%)$ and $54(30.2 \%)$ of school leaders and teachers respectively rated as low. In addition, $5(41.7 \%)$ and $34(19 \%)$ of school leaders and teachers respectively rated as medium. Moreover, $0(0 \%)$ and $21(11.7 \%)$ of school leaders and teachers respectively rated as high. Furthermore, 1(8.3\%) and 7(3.9\%) of school leaders and teachers respectively rated as very high. However, the sum of the total respondents' percentage values rated $8(4.2 \%)$ as very high, $21(11 \%)$ as high, 39(20.4\%) as medium, 58(30.4\%) as low and $65(34 \%)$ as very low. To compare the agreement of school leaders and teachers on stakeholders' involvement in deciding construction of new buildings the chi-square was computed and revealed $\mathrm{X}^{2}$ (5.936) sig. (.204). This implies that participative decision making took place in this aspect of school area was low. The document review confirmed the above findings there was no school document that showed stakeholders' participation in deciding on school building. 
Table 6: Factors affecting the principals' decision-making practice

\begin{tabular}{|c|c|c|c|c|c|c|c|c|c|c|}
\hline \multirow{2}{*}{$\begin{array}{l}\mathrm{N} \\
\mathrm{O}\end{array}$} & \multirow[t]{2}{*}{ Items } & \multirow{2}{*}{$\begin{array}{l}\text { Response } \\
\text { rating scale }\end{array}$} & \multicolumn{2}{|c|}{ School leaders } & \multicolumn{2}{|c|}{ Teachers } & \multicolumn{2}{|l|}{ Total } & \multirow[t]{2}{*}{$X^{2}$} & \multirow[t]{2}{*}{ Sig. } \\
\hline & & & $\mathrm{F}$ & $\%$ & $F$ & $\%$ & $F$ & $\%$ & & \\
\hline \multirow[t]{5}{*}{1} & School principal & $\mathrm{VH}$ & 0 & 0 & 59 & 33 & 59 & 30.9 & \multirow[t]{5}{*}{17.185} & \multirow[t]{5}{*}{.002} \\
\hline & fails to use & $\mathrm{H}$ & 0 & 0 & 47 & 26.3 & 47 & 24.6 & & \\
\hline & community & $\mathrm{M}$ & 4 & 33.3 & 33 & 18.4 & 37 & 19.4 & & \\
\hline & comments, & $\mathrm{L}$ & 6 & 50 & 30 & 16.8 & 36 & 18.8 & & \\
\hline & $\begin{array}{l}\text { suggestions and } \\
\text { opinions for } \\
\text { decision-making } \\
\text { process. }\end{array}$ & $\mathrm{VL}$ & 2 & 16.7 & 10 & 5.6 & 12 & 6.3 & & \\
\hline \multirow[t]{5}{*}{2} & \multirow{5}{*}{$\begin{array}{l}\text { The principals' } \\
\text { practice } \\
\text { autocratic } \\
\text { leadership style. }\end{array}$} & $\mathrm{VH}$ & 0 & 0 & 29 & 16.2 & 29 & 15.2 & \multirow[t]{5}{*}{18.192} & \multirow[t]{5}{*}{.001} \\
\hline & & $\mathrm{H}$ & 0 & 0 & 49 & 27.4 & 49 & 25.7 & & \\
\hline & & $\mathrm{M}$ & 3 & 25 & 35 & 19.6 & 38 & 19.9 & & \\
\hline & & $\mathrm{L}$ & 9 & 75 & 42 & 23.5 & 51 & 26.7 & & \\
\hline & & VL & 0 & 0 & 24 & 13.4 & 24 & 12.6 & & \\
\hline \multirow[t]{5}{*}{3} & \multirow{5}{*}{$\begin{array}{l}\text { Principal's less } \\
\text { concern for } \\
\text { people (stick to } \\
\text { the rules). }\end{array}$} & $\mathrm{VH}$ & 0 & 0 & 10 & 5.6 & 10 & 5.2 & \multirow[t]{5}{*}{4.616} & \multirow[t]{5}{*}{.329} \\
\hline & & $\mathrm{H}$ & 0 & 0 & 37 & 20.7 & 37 & 19.4 & & \\
\hline & & $\mathrm{M}$ & 5 & 41.7 & 54 & 30.2 & 59 & 30.9 & & \\
\hline & & $\mathrm{L}$ & 5 & 41.7 & 47 & 26.3 & 52 & 27.2 & & \\
\hline & & VL & 2 & 16.7 & 31 & 17.3 & 33 & 17.3 & & \\
\hline \multirow[t]{5}{*}{4} & \multirow{5}{*}{$\begin{array}{l}\text { Lack of trust } \\
\text { and positive } \\
\text { relationship } \\
\text { between } \\
\text { stakeholders and } \\
\text { principal. }\end{array}$} & $\mathrm{VH}$ & 0 & 0 & 46 & 25.7 & 46 & 24.1 & \multirow[t]{5}{*}{14.550} & .006 \\
\hline & & $\mathrm{H}$ & 0 & 0 & 50 & 27.9 & 50 & 26.2 & & \\
\hline & & $\mathrm{M}$ & 6 & 50 & 45 & 25.1 & 51 & 26.7 & & \\
\hline & & $\mathrm{L}$ & 5 & 41.7 & 25 & 14 & 30 & 15.7 & & \\
\hline & & $\mathrm{VL}$ & 1 & 8.3 & 13 & 7.3 & 14 & 7.3 & & \\
\hline 5 & There is lack of & $\mathrm{VH}$ & 0 & 0 & 50 & 27.9 & 50 & 26.2 & 9.438 & .051 \\
\hline & transparency & $\mathrm{H}$ & 1 & 8.3 & 44 & 24.6 & 45 & 23.6 & & \\
\hline & between school & M & 5 & 41.7 & 43 & 24 & 48 & 25.1 & & \\
\hline & principal and & $\mathrm{L}$ & 5 & 41.7 & 32 & 17.9 & 37 & 19.4 & & \\
\hline & teachers & VL & 1 & 8.3 & 10 & 5.6 & 11 & 5.8 & & \\
\hline 6 & There is & $\mathrm{VH}$ & 0 & 0 & 69 & 38.5 & 69 & 36.1 & 12.953 & .012 \\
\hline & interference of & $\mathrm{H}$ & 6 & 50 & 48 & 26.8 & 54 & 28.3 & & \\
\hline & political & $\mathrm{M}$ & 5 & 41.7 & 26 & 14.5 & 31 & 16.2 & & \\
\hline & officials. & $\mathrm{L}$ & 1 & 8.3 & 22 & 12.3 & 23 & 12 & & \\
\hline & & VL & 0 & 0 & 14 & 7.8 & 14 & 7.3 & & \\
\hline 7 & School principal & $\mathrm{VH}$ & 0 & 0 & 47 & 26.3 & 47 & 24.6 & 20.906 & .000 \\
\hline & fails to delegate & $\mathrm{H}$ & 0 & 0 & 53 & 29.6 & 53 & 27.7 & & \\
\hline & authority and & $\mathrm{M}$ & 5 & 41.7 & 45 & 25.1 & 50 & 26.2 & & \\
\hline & $\begin{array}{l}\text { responsibility to } \\
\text { teachers }\end{array}$ & $\mathrm{L}$ & 7 & 58.3 & 26 & 14.5 & 33 & 17.3 & & \\
\hline & & VL & 0 & 0 & 8 & 4.5 & 8 & 4.2 & & \\
\hline 8 & School principal & VH & 4 & 33.3 & 53 & 29.6 & 57 & 29.8 & 31.131 & .000 \\
\hline & fails of keeping & $\mathrm{H}$ & 1 & 8.3 & 45 & 25.1 & 46 & 24.1 & & \\
\hline & communication & $\mathrm{M}$ & 0 & 0 & 43 & 24 & 43 & 22.5 & & \\
\hline & & $\mathrm{L}$ & 1 & 8.3 & 28 & 15.6 & 29 & 15.2 & & \\
\hline
\end{tabular}




\begin{tabular}{|c|c|c|c|c|c|c|c|c|c|c|}
\hline & $\begin{array}{ll}\text { channels } & \text { open } \\
\text { for staff } & \end{array}$ & $\overline{V L}$ & 6 & 50 & 10 & 5.6 & 16 & 8.4 & & \\
\hline \multirow[t]{5}{*}{9} & \multirow{5}{*}{$\begin{array}{l}\text { There is lack of } \\
\text { coordination } \\
\text { and cooperation } \\
\text { among school } \\
\text { principal and } \\
\text { staff }\end{array}$} & VH & 0 & 0 & 33 & 18.4 & 33 & 17.3 & 17.391 & .002 \\
\hline & & $\mathrm{H}$ & 1 & 8.3 & 50 & 27.9 & 51 & 26.7 & & \\
\hline & & M & 2 & 16.7 & 36 & 20.1 & 38 & 19.9 & & \\
\hline & & $\mathrm{L}$ & 9 & 75 & 40 & 22.3 & 49 & 25.7 & & \\
\hline & & VL & 0 & 0 & 20 & 11.2 & 20 & 10.5 & & \\
\hline \multirow[t]{5}{*}{10} & School principal & VH & 0 & 0 & 24 & 13.4 & 24 & 12.6 & 11.438 & .022 \\
\hline & fails & $\mathrm{H}$ & 0 & 0 & 39 & 21.8 & 39 & 20.4 & & \\
\hline & encourage social & M & 6 & 50 & 55 & 30.7 & 61 & 31.9 & & \\
\hline & relationships & $\mathrm{L}$ & 6 & 50 & 37 & 20.7 & 43 & 22.5 & & \\
\hline & among staff & VL & 0 & 0 & 24 & 13.4 & 24 & 12.6 & & \\
\hline \multirow[t]{5}{*}{11} & School principal & VH & 2 & 16.7 & 55 & 30.7 & 57 & 29.8 & 36.828 & .000 \\
\hline & fails to motivate & $\mathrm{H}$ & 1 & 8.3 & 52 & 29.1 & 53 & 27.7 & & \\
\hline & staff to & $\mathrm{M}$ & 2 & 16.7 & 34 & 19 & 36 & 18.8 & & \\
\hline & participate in & $\mathrm{L}$ & 0 & 0 & 27 & 15.1 & 27 & 14.1 & & \\
\hline & $\begin{array}{l}\text { school decision- } \\
\text { making }\end{array}$ & VL & 7 & 58.3 & 11 & 6.1 & 18 & 9.4 & & \\
\hline \multirow[t]{5}{*}{12} & There is lack of & $\mathrm{VH}$ & 0 & 0 & 50 & 27.9 & 50 & 26.2 & 18.832 & .001 \\
\hline & motivation by & $\mathrm{H}$ & 0 & 0 & 61 & 34.1 & 61 & 31.9 & & \\
\hline & principal to & M & 6 & 50 & 31 & 17.3 & 37 & 19.4 & & \\
\hline & inyolve staff & $\mathrm{L}$ & 5 & 41.7 & 26 & 14.5 & 31 & 16.2 & & \\
\hline & & VL & 1 & 8.3 & 11 & 6.1 & 12 & 6.3 & & \\
\hline \multirow[t]{5}{*}{13} & Staffs belief that & VH & 0 & 0 & 28 & 15.6 & 28 & 14.7 & 14.454 & .006 \\
\hline & decision- & $\mathrm{H}$ & 7 & 58.3 & 43 & 24 & 50 & 26.2 & & \\
\hline & making is not & M & 5 & 41.7 & 35 & 19.6 & 40 & 20.9 & & \\
\hline & their & $\mathrm{L}$ & 0 & 0 & 42 & 23.5 & 42 & 22 & & \\
\hline & $\begin{array}{l}\text { responsibility } \\
\text { but the } \\
\text { responsibility of } \\
\text { school } \\
\text { principals }\end{array}$ & VL & 0 & 0 & 31 & 17.3 & 31 & 16.2 & & \\
\hline \multirow[t]{5}{*}{14} & Unwillingness & VH & 1 & 8.3 & 23 & 12.8 & 24 & 12.6 & 11.405 & .022 \\
\hline & of staffs to & $\mathrm{H}$ & 5 & 41.7 & 24 & 13.4 & 29 & 15.2 & & \\
\hline & actively & M & 6 & 50 & 63 & 35.2 & 69 & 36.1 & & \\
\hline & participate in & $\mathrm{L}$ & 0 & 0 & 40 & 22.3 & 40 & 20.9 & & \\
\hline & $\begin{array}{l}\text { school decision- } \\
\text { making process } \\
\text { that concerns } \\
\text { them }\end{array}$ & VL & 0 & 0 & 29 & 16.2 & 29 & 15.2 & & \\
\hline
\end{tabular}

With item 1 of Table 6 , the respondents were asked to rate whether or not preparatory school principals use stakeholders' comments, suggestions and opinions in the decision-making process. Accordingly, $2(16.7 \%)$ and $10(5.6 \%)$ of school leaders and teachers respectively rated as very low. On the other hand, $6(50 \%)$ and $30(16.8 \%)$ of school leaders and teachers respectively rated as low. In addition, 4(33.3\%) and $33(18.4 \%)$ of school leaders and teachers respectively rated as medium. Moreover, $0(0 \%)$ and $47(26.3 \%)$ of school leaders and teachers respectively rated as high. Furthermore, $0(0 \%)$ and $59(33 \%)$ of school leaders and teachers respectively rate as very high. However, the sum of the total respondents' percentage values rated $59(30.9 \%)$ as very high, $47(24.6 \%)$ as agree, $37(19.4 \%)$ as medium, 36(18.8\%) as low and 
$12(6.3 \%)$ as very low. To compare the agreement of school leaders and teachers on failure of preparatory school principals use stakeholders' comments, suggestions and opinions in the decision-making process the chi-square was computed and revealed $\mathrm{X}^{2}$ (17.185) sig. (.002).

Item 2 of Table 6, relates to whether or not the principals' practice autocratic leadership style and if this, affects principals' decision-making practice. As to this, $0(0 \%)$ and 24(13.4\%) of school leaders and teachers respectively rated as very low. On the other hand, 9(75\%) and 42(23.5\%) of school leaders and teachers respectively rated as low. In addition, 3(25\%) and 35(19.6\%) of school leaders and teachers respectively rated as medium. Moreover, $0(0 \%)$ and $49(27.4 \%)$ of school leaders and teachers respectively rated as high. Furthermore, $0(0 \%)$ and $29(16.2 \%)$ of school leaders and teachers respectively rate as very high. However, the sum of the total respondents' percentage values rated $29(15.2 \%)$ as very high, $49(25.7 \%)$ as high, 38(19.9\%) as medium, 51(26.7\%) as low and 24(12.6\%) as very low. To compare the agreement of school leaders and teachers on principals' practice autocratic leadership style affects principals decision-making practice the chi-square was computed and revealed $\mathrm{X}^{2}$ (18.192) sig. (.001).

As can be seen from item 3 of Table 6, the respondents were asked whether principals' less concern for people (stick to the rules) affects principals decision-making practice in preparatory schools of West Shoa or not. Accordingly, 2(16.7\%) and 31(17.3\%) of school leaders and teachers respectively rated as very low. On the other hand, 5(41.7\%) and 47(26.3\%) of school leaders and teachers respectively rated as low. In addition, $5(41.7 \%)$ and $54(30.2 \%)$ of school leaders and teachers respectively rated as medium. Moreover, $0(0 \%)$ and 37(20.7\%) of school leaders and teachers respectively rated as high. Furthermore, $0(0 \%)$ and $10(5.6 \%)$ of school leaders and teachers respectively rate as very high. However, the sum of the total respondents' percentage values rated 10(5.2\%) as very high, 37(19.4\%) as high, 59(30.9\%) as medium, fifty-two (27.2\%) as low and 33(17.3\%) as very low. To compare the agreement of school leaders and teachers on principals' less concern for people (stick to the rules) affects principals decision-making practice the chi-square was computed and revealed $\mathrm{X}^{2}$ (4.616) sig. (.329).

Item 4 of Table 6 , relates to whether or not lack of trust and positive relationship between stakeholders and principal affects principals' decision-making practice in schools. As to this, 1(8.3\%) and 13(7.3\%) of school leaders and teachers respectively rated as very low. On the other hand, 5(41.7\%) and 25(14\%) of school leaders and teachers respectively rated as low. In addition, 6(50\%) and 45(25.1\%) of school leaders and teachers respectively rated as medium. Moreover, $0(0 \%)$ and 50(27.9\%) of school leaders and teachers respectively rated as high. Furthermore, $0(0 \%)$ and $46(25.7 \%)$ of school leaders and teachers respectively rate as very high. However, the sum of the total respondents' percentage values rated $46(24.1 \%)$ as very high, 55(26.2\%) as high, 51(26.7\%) as medium, 30(15.7\%) as low and $14(7.3 \%)$ as very low. To compare the agreement of school leaders and teachers on lack of trust and positive relationship between stakeholders and principal affects principals' decision-making practice in schools the chi-square was computed and revealed $\mathrm{X}^{2}$ (14.550) sig. (.006).

As can be noticed from item 5 of Table 6, the respondents asked whether or not lack of transparency between school principal and teachers and if this affects principals' decision-making practice in schools. Accordingly, 1(8.3\%) and 10(5.6\%) of school leaders and teachers respectively rated as very low. On the other hand, 5(41.7\%) and 32(17.9\%) of school leaders and teachers respectively rated as low. In addition, $5(41.7 \%)$ and $43(24 \%)$ of school leaders and teachers respectively rated as medium. Moreover, $1(8.3 \%)$ 
and $44(24.6 \%)$ of school leaders and teachers respectively rated as high. Furthermore, $0(0 \%)$ and $50(27.9 \%)$ of school leaders and teachers respectively rate as very high. However, the sum of the total respondents' percentage values rated $50(26.2 \%)$ as very high, $45(23.6 \%)$ as high, 48(25.1\%) as medium, $37(19.4 \%)$ as low and $11(5.8 \%)$ as very low. To compare the agreement of school leaders and teachers on lack of transparency between school principal and teachers and if this affects principals' decision-making practice in schools the chi-square was computed and revealed $\mathrm{X}^{2}$ (9.438) sig. (.051).

Item 6 of Table 6, relates to whether or not interference of political officials affects principals' decisionmaking practice in schools. As to this, $0(0 \%)$ and $14(7.8 \%)$ of school leaders and teachers respectively rated as very low. On the other hand, $1(8.3 \%)$ and 22(12.3\%) of school leaders and teachers respectively rated as low. In addition, 5(41.7\%) and 26(14.5\%) of school leaders and teachers respectively rated as medium. Moreover, 6(50\%) and 48(26.8\%) of school leaders and teachers respectively rated as high. Furthermore, $0(0 \%)$ and $69(38.5 \%)$ of school leaders and teachers respectively rate as very high. However, the sum of the total respondents' percentage values rated $69(36.1 \%)$ as very high, 54(28.3\%) as high, $31(16.2 \%)$ as medium, twenty-three $(12 \%)$ as low and $14(7.3 \%)$ as very low. To compare the agreement of school leaders and teachers on interference of political officials affects principals' decision-making practice in schools the chi-square was computed and revealed $X^{2}$ (12.953) sig. (.012).

As can be noticed from item 7 of Table 6, the respondents were asked to rate whether or not failure of principals to delegate authority and responsibility to teachers is an affecting factor to principals' decisionmaking practice in schools. Accordingly, $0(0 \%)$ and $8(4.5 \%)$ of school leaders and teachers respectively rated as very low. On the other hand, 7(58.3\%) and 26(14.5\%) of school leaders and teachers respectively rated as low. In addition, 5(41.7\%) and 45(25.1\%) of school leaders and teachers respectively rated as medium. Moreover, $0(0 \%)$ and 53(29.6\%) of school leaders and teachers respectively rated as high. Furthermore, $0(0 \%)$ and $47(26.3 \%)$ of school leaders and teachers respectively rate as very high. However, the sum of the total respondents' percentage values rated $47(24.6 \%)$ as very high, $53(27.7 \%)$ as high, $50(26.2 \%)$ as medium, $33(17.3 \%)$ as low and $8(4.2 \%)$ as very low. To compare the agreement of school leaders and teachers on failure of principals to delegate authority and responsibility to teachers is an affecting factor to principals' decision-making practice in schools the chi-square was computed and revealed $X^{2}$ (20.906) sig. (.000). To support this data the researcher conducted interview with PTSA and KETB heads. The interviewed PTSA and KETB heads said "Sometimes school principals delegate authority and responsibility to stakeholders in the areas of teaching and learning process. However, most of the time principals lack interest, confidence and did not legally list of activities delegated to the delegate that affects the delegate to fully exercise their decision-making participation in schools". From this one could realize that, in preparatory schools under the study failure of principals to delegate authority and responsibility to teachers and other staffs was highly affecting factor to principals' decision-making practice in Preparatory Schools of West Shoa Zone.

As can be noticed from item 8 of Table 6, the respondents were asked whether fail of keeping communication channels open for staff is a constraint to principals' decision-making practice in preparatory schools of West Shoa or not. As to this, 6(50\%) and 10(5.6\%) of school leaders and teachers respectively rated as very low. On the other hand, $1(8.3 \%)$ and $28(15.6 \%)$ of school leaders and teachers respectively rated as low. In addition, $0(0 \%)$ and $43(24 \%)$ of school leaders and teachers respectively rated 
as medium. Moreover, 1(8.3\%) and 45(25.1\%) of school leaders and teachers respectively rated as high. Furthermore, 4(33.3\%) and 53(29.6\%) of school leaders and teachers respectively rate as very high. However, the sum of the total respondents' percentage values rated $57(29.8 \%)$ as very high, $46(24.1 \%)$ as high, $43(22.5 \%)$ as medium, $29(15.2 \%)$ as low and 16(8.4\%) as very low. To compare the agreement of school leaders and teachers on fail of keeping communication channels open for staff is a constraint to principals' decision-making practice in preparatory schools of West Shoa the chi-square was computed and revealed $\mathrm{X}^{2}$ (31.131) sig. (.000). This indicates that there was lack of communication channels between school leaders and stakeholders in preparatory school under the study. As regards this research findings indicate that ineffective communication will result in conflict, disorder, misunderstanding and lack of confidence in school administration (Kindiki, 2010). He also argued that lack of a proper hierarchy of authority in a school setting would also lead to poor communication in the school. De Grauwe et al. (2011), also write that this may be due to lack of stakeholders' full participation in decision-making practices on different school activities. However, Ahmed (2011) stated that school administrators need to make sure that the alternative is clearly understood. This is accomplished by communicating the decision to all involved staff. Effective communication is necessary for effectively implementing decisions, school administrators need to encourage acceptance of the alternative as a necessary course of action. To avoid ineffective communication in school setting there should be open communication channels that participating the staff members. In line with this Walker (2000), writes when everyone in an organization participates in the decision-making process, organizational communication is much more effective and everyone produces more efficient results by sharing decision-making with other employees, participants eventually achieve organization objectives that influence them that consequently lead to good decision making practice.

As suggestions and comments collected though open-ended questions revealed, different factors were created communication barriers between stakeholders and school principals, which in turn affect decisionmaking practice in schools were lack of communication skills, existence of information gap, conflicts and disagreement between principals and stakeholders. As regards this Okorie (2010), also identified time, communication overload, language and cultural differences are barriers of communication in school setting. Consequently, decision-making practices of principals were affected by failure of communication happening between teachers and school leaders.

As can be noticed from item 9 of Table 6 , the respondents were asked to rate whether lack of coordination and cooperation among school principal and staff is a constraint to principals' decision-making practice in schools or not. Accordingly, $0(0 \%)$ and $20(11.2 \%)$ of school leaders and teachers respectively rated as very low. On the other hand, 9(75\%) and 40(22.3\%) of school leaders and teachers respectively rated as low. In addition, $2(16.7 \%)$ and $36(20.1 \%)$ of school leaders and teachers respectively rated as medium. Moreover, $1(8.3 \%)$ and 50(27.9\%) of school leaders and teachers respectively rated as high. Furthermore, $0(0 \%)$ and $33(18.4 \%)$ of school leaders and teachers respectively rate as very high. However, the sum of the total respondents' percentage values rated 33(17.3\%) as very high, 51(26.7\%) as high, 38(19.9\%) as medium, $49(25.7 \%)$ as low and $20(10.5 \%)$ as very low. To compare the agreement of school leaders and teachers on lack of coordination and cooperation among school principal and staff is a constraint to principals' decision-making practice in schools the chi-square was computed and revealed $\mathrm{X}^{2}(17.391)$ sig. (.002). 
As can be shown from item 10 of Table 6, the respondents were asked to rate whether failure of principals to encourage social relationships among staff is a constraint to principals' decision-making practice in schools or not. As to this, $0(0 \%)$ and $24(13.4 \%)$ of school leaders and teachers respectively rated as very low. On the other hand, $6(50 \%)$ and $37(20.7 \%)$ of school leaders and teachers respectively rated as low. In addition, 6(50\%) and 55(30.7\%) of school leaders and teachers respectively rated as medium. Moreover, $0(0 \%)$ and $39(21.8 \%)$ of school leaders and teachers respectively rated as high. Furthermore, $0(0 \%)$ and $24(13.4 \%)$ of school leaders and teachers respectively rate as very high. However, the sum of the total respondents' percentage values rated $24(12.6 \%)$ as very high, 39(20.4\%) as high, 61(31.9\%) as medium, forty-three $(22.5 \%)$ as low and $24(12.6 \%)$ as very low. To compare the agreement of school leaders and teachers on failure of principals to encourage social relationships among staff is a constraint to principals' decision-making practice in schools the chi-square was computed and revealed $\mathrm{X}^{2}$ (11.438) sig. (.022).

As can be shown from item 11 of Table 6, the respondents were asked to rate whether failure of principals to motivate staff to give ideas and suggestion for school decision-making is a constraint to principals decision-making practice in schools or not. Accordingly, 7(58.3\%) and 11 (6.1\%) of school leaders and teachers respectively rated as very low. On the other hand, $0(0 \%)$ and $27(15.1 \%)$ of school leaders and teachers respectively rated as low. In addition, $2(16.7 \%)$ and $34(19 \%)$ of school leaders and teachers respectively rated as medium. Moreover, $1(8.3 \%)$ and $52(29.1 \%)$ of school leaders and teachers respectively rated as high. Furthermore, 2(16.7\%) and 55(30.7\%) of school leaders and teachers respectively rate as very high. However, the sum of the total respondents' percentage values rated $57(29.8 \%)$ as very high, $53(27.7 \%)$ as high, 36(18.8\%) as medium, 27(14.1\%) as low and 18(9.4\%) as very low. To compare the agreement of school leaders and teachers on failure of principals to motivate staff to give ideas and suggestion for school decision-making is a constraint to principals' decision-making practice in schools the chi-square was computed and revealed $\mathrm{X}^{2}$ (36.828) sig. (.000). To support the above findings the researcher conducted interview with PTSA and KETB heads. Some of the PTSA and KETB heads said, "Principals were not always motivating the stakeholders properly. Therefore, the stakeholders reserved to give ideas, suggestions and comments that promote school improvement". From this, it is understood that principals of the study area were not motivate stakeholders on school activities in general and decision-making practice in particular that brings to poor decision-making practice in schools. Contrary to this finding, Somech (2010) writes participatory decision-making practice promotes school stakeholders and teachers out comes through two motivational mechanisms; organizational commitment and teacher and school community empowerment. PDM provides teacher and school community opportunity to be involved and exert influence on decision-making practices. Their participation is believed to promote commitment to the decisions that made and to increase willingness to execute them in their work.

Item 12 of Table 6, relates to rate whether or not lack of motivation by principal to involve staff is a constraint to principals' decision-making practice in schools. As to this, $1(8.3 \%)$ and 11(6.1\%) of school leaders and teachers respectively rated as very low. On the other hand, 5(41.7\%) and 26(14.5\%) of school leaders and teachers respectively rated as low. In addition, 6(50\%) and 31(17.3\%) of school leaders and teachers respectively rated as medium. Moreover, $0(0 \%)$ and $61(34.1 \%)$ of school leaders and teachers respectively rated as high. Furthermore, $0(0 \%)$ and $50(27.9 \%)$ of school leaders and teachers respectively rate as very high. However, the sum of the total respondents' percentage values rated $50(26.2 \%)$ as very 
high, 61(31.9\%) as high, 37(19.4\%) as medium, 31(16.2\%) as low and 12(6.3\%) as very low. To compare the agreement of school leaders and teachers on lack of motivation by principal to involve staff is a constraint to principals' decision-making practice in schools the chi-square was computed and revealed $\mathrm{X}^{2}$ (18.832) sig. (.001).

As can be seen from item 13 of Table 6, the respondents were asked to rate whether decision-making is not staff responsibility, but the responsibility of school principals is a constraint to principals' decisionmaking practice in schools or not. Accordingly, $0(0 \%)$ and 31(17.3\%) of school leaders and teachers respectively rated as very low. On the other hand, $0(0 \%)$ and $42(23.5 \%)$ of school leaders and teachers respectively rated as low. In addition, 5(41.7\%) and 35(19.6\%) of school leaders and teachers respectively rated as medium. Moreover, $7(58.3 \%)$ and $43(24 \%)$ of school leaders and teachers respectively rated as high. Furthermore, $0(0 \%)$ and $28(15.6 \%)$ of school leaders and teachers respectively rate as very high. However, the sum of the total respondents' percentage values rated $28(14.7 \%)$ as very high, $50(26.2 \%)$ as high, $40(20.9 \%)$ as medium, $42(22 \%)$ as low and $31(16.2 \%)$ as very low. To compare the agreement of school leaders and teachers on whether decision-making is not staff responsibility, but the responsibility of school principals is a constraint to principals' decision-making practice in schools the chi-square was computed and revealed $\mathrm{X}^{2}$ (14.454) sig. (.006).

As can be noticed from item 14 of Table 6, the respondents were asked to rate whether unwillingness of staff to actively participate in school decision-making process that concerns them affects principals' decision-making practice in schools or not. As to this, $0(0 \%)$ and $29(16.2 \%)$ of school leaders and teachers respectively rated as very low. On the other hand, $0(0 \%)$ and $40(22.3 \%)$ of school leaders and teachers respectively rated as low. In addition, six (50\%) and 63(35.2\%) of school leaders and teachers respectively rated as medium. Moreover, $5(41.7 \%)$ and $24(13.4 \%)$ of school leaders and teachers respectively rated as high. Furthermore, $1(8.3 \%)$ and $23(12.8 \%)$ of school leaders and teachers respectively rate as very high. However, the sum of the total respondents' percentage values rated $24(12.6 \%)$ as very high, $29(15.2 \%)$ as high, $69(36.1 \%)$ as medium, $40(20.9 \%)$ as low and 29(15.2\%) as very low. To compare the agreement of school leaders and teachers on whether unwillingness of staff to actively participate in school decisionmaking process that concerns them affects principals' decision-making practice in schools the chi-square was computed and revealed $\mathrm{X}^{2}(11.405)$ sig. (.022).

To substantiate the above findings the researcher collected data through open-ended questions and it was showed that, staffs' motivation was affected because of some problems observed on the part of school principals. These major problems of teachers' performance appraisal (sometimes school principals are not evaluating teachers according to what they perform), PTSAs' level of education (during decision-making process they are favoring the principal's ideas), disagreement between school principals and teachers, too much relationship between some teachers and school principals. Especially principals, vice principals, department heads and PTSA members play a great role in selecting model teachers (those performing good deeds) for rewards, attending workshops and training, and assign teachers as unit leaders, department heads and coordinators of clubs, partiality was commonly observed.

As regards this, Bennell (2010) writes that incentives for schools and teachers in the public education system to perform well are frequently weak due to ineffective incentives and sanctions, poor human 
resource management, workload and working environment, which tends to lower teachers' self-esteem and is generally demoting them. This highly affects teachers' interest of performing tasks. Because of these problems some teachers were not attending meeting. Bennell (2010) also noted that poor motivation and lack of accountability is widely reported to result in staffs' absenteeism in less-developing countries. This implies that teachers' participation in decision-making was highly affected by school leaders' way of motivating teachers and other staffs.

Overall, factors that affect principals decision making practices were leadership factors like lack of experience, transparency, good management skill, training and support, problem of delegating authority, work, responsibility, lack of coordination and cooperation, partiality, political outlook, lack of communication skills, school leaders unable to implement decisions already made timely, lack of time, lack of good ethics.

\section{Conclusion and Recommendations}

\subsection{Conclusion}

Based on the analysis of the data and the major findings of the study, the following conclusions were derived in relation to basic questions of the study:

1. The extent of stakeholders' participation in decision-making relating to planning school activities, budget and income generation; and school building was in adequate. Stakeholders' participation in implementing school curriculum and instruction related decision was relatively high. Generally, the extent of stakeholders' participation in decision-making in preparatory schools of West Shoa Zone was minimal. Less attention was given to stakeholders' contribution to efficiency and effectiveness of school performance through involvement in decision making. This, thus, affects the overall activities of school in general and decision-making process in particular.

2. Concerning factors that affected the principals' decision-making practice, the study revealed that most of the factors relate to poor managerial role of the principals. It was also learned that principals lacked relevant training and/or qualification. Consequently, it could be concluded that principals failed to practice decision-making through such management functions as delegation, communication, motivation, etc. Moreover, it could be concluded that the preparatory schools' principals lacked the requisite skill, knowledge and attitude to attract and help stakeholders partake in the schools' decision-making.

\subsection{Recommendations}

Based on the summary of major findings and conclusions made above, the following recommendations have been given:

1. The extent of stakeholders' participation in decision-making was found to be low because of lack of awareness, limited knowledge, skills \& attitude. It was learned from the responses that this owed to poor relationship they had with school principals. Therefore, it is advisable that school leaders: 
- identify knowledge, skills \& attitude gaps of stakeholders,

- create conducive work environment,

- ensure smooth relationship and

- develop sense of transparency among stakeholders provide continual training.

2. Stakeholders' involvement in decision-making in schools depends largely on school leaders' knowledge, skills and attitude to participate them in school decision-making. In view of this, it was found that some of the principals in the preparatory schools under the study lacked relevant qualification and/or training which led to failure to involve stakeholders in decisions. Hence, WEO, in collaboration with the concerned levels of the education system, is advised to strengthen training in school leadership which is provided by Universities. Besides, it is good if short term trainings are continuously offered on-the-job.

3. Principals' decision-making practice seems to be very poor due to lack of transparency, lack of encouragement, poor participation, poor communication, etc. So, school principals, members of KETB \& PTSA need to:

- ensure transparency,

- enhance communication,

- promote participation of stakeholders,

- maintain good working relationship between staff and principals, etc.

4. As the study showed, political interference/external factor highly affected the principals' decisionmaking practices. Most of the time, most principals' decisions were contrary to the school rules $\&$ regulations because of external influence. Hence, the researcher strongly recommends that the government, in general, \& school principals, in particular, ensure secularism of schools while also minimizing prevailing interference of external bodies in school decisions.

5. This research focused on the assessment of the practice, extent of stakeholders' participation in different areas of school decision-making, how stakeholders perceive and factors affect principals decision making practice in their schools. Despite the attempt, the researcher learned from this research undertaking that a lot remains to be done. Consequently, the researcher recommended comprehensive further study to investigate the root causes of poor practice of decision-making, poor participation of stakeholders and other related factors in a wider coverage.

\section{References}

Balcha, D. (2012). Teachers' Participation in Decision Making Process in Bale Zone. Unpublished Master's Thesis. AAU.

Chen, Y.F., \& Tjosvold, D. (2006). Participative leadership by American and Chinese managers in China: The role of relationships. Journal of Management Studies, 43 (8), 1727-1752.

Creswell, J. W. (2012). Educational research: planning, conducting, and evaluating quantitative and qualitative research. Boston: MA Pearson. 
De Grauwe, A., Candy, L., Tiberius, B., Pulane, J., Lefoka, M., Samuel, K., \& Wilson, A. (2011).

Strengthening local actors: The path to decentralizing education. Kenya, Uganda, and Lesotho, Paris: International Institute for Educational Planning and UNESCO.

Desalegn, G. (2014). The practices of teachers' involvement in decision-making in government secondary schools of jimma town . Unpublished Master's Thesis. JU.

Dunne, M., Kwame, A., \& Sara, H. (2012). School processes, local governance, and community participation: Understanding access, CREATE Pathways to Access: Brighton: Consortium for Educational Access, Transitions and Equity (Vol. 6). University of Sussex.

Furi, G. (2016). Practices of principals in enhancing participatory decision-making in secondary schools of West Arsi Zone, Oromia Regional State. MA Thesis.

Marshall, V. (2012). Participation in decision making: A matter of context. Leadership and Organizational Development Journal, 25 (8), 646-662.

MoE (2010a). Educational Sector Development Program IV (ESDP IV): Program Action Plan (PAP) . Addis Ababa.

MoE (2010b). Education Sector Development Programme IV (ESDP IV). Addis Ababa.

Olanie, D. (2015). Decision making practices of government secondary school leaders of Meta Woreda, East Hararghe Zone, Oromia Regional State. Unpublished Master's Thesis, HU.

Oromia Education Bureau (2011). School Improvement Program (SIP) Manual Finfine: Oromia Regional State, Oromia, Ethiopia.

Shibeshi, A. (2011). Theories of Educational Management Set Readers (Vols. I-III ). Addis Ababa.

Singh, A.S. \& Masuku, M. B. (2014). Sampling techniques \& determination of sample size in applied statistics research: An overview. International Journal of Economics, Commerce and Management, 2(11), 1-22.

Somech, A. (2010). Participative decision making in school: A Mediating- Moderating outcomes analytical framework for understanding school and teacher. Retrieved from http://eaq.sagepub. com /content/46/2/174.

UNESCO (2014). Decentralizing Education Management Newsletter- a quarterly publication in English and French. Paris: International Institute for Capacity Building in Africa.

Walker, E.M. (2000). Decentralization and participatory decision making: Implementing School-based management in the Abbott districts. Research Brief, 1(1), 3-23.

Workneh, A. (2012). School management and decision-making in Ethiopian government schools: Evidence from the young lives qualitative school survey. Oxford Department of International Development (ODID). University of Oxford.

Yelfign, T. (2010). Teachers' Participation in Decision - making at school. Amhara National Regional State Education Bureau, 1(1). 